\title{
The Role of Vitamin D deficiency in COVID-19 related deaths in BAME, Obese and Other High-risk Categories
}

Eshani King 2.5.2020. Updated 4.6.2020

\section{Abstract}

It is now widely known that a disproportionate number of COVID-19 related mortalities in the UK have been in non-white, BAME populations [2]. The obese, diabetics, hypertensives and the elderly have also been disproportionately affected. BAME doctors account for $94 \%$ of total deaths of doctors but comprise $44 \%$ of doctors [1]. The suggestion that these deaths result from deprivation does not fit with the high numbers of deaths of doctors and others in higher socio-economic classes; there must be a different and perhaps more comprehensive explanation.

This review examines the compelling body of evidence strongly implicating varying levels of serum vitamin $D$ levels in the significantly disparate outcomes between different groups of people and between different countries. It explores the extent of vitamin D deficiency, highlighting countries and categories of people most likely to be deficient. It demonstrates that the UK suffers from exceptionally high levels of vitamin D deficiency with serum levels averaging only $20 \mathrm{ng} / \mathrm{ml}$, half the optimal level; It examines the strong body of existing evidence connecting vitamin $D$ deficiency to increased respiratory tract infections highlighting the central epigenetic role of vitamin $D$ in immune system responses during a respiratory tract infection with SARS-CoV-2; It reviews research flagging correlations between COVID-19 outcomes and vitamin D deficiency and studies providing the first direct evidence linking low vitamin D status with worse outcomes from COVID-19. Cautions regarding future trial designs and lack of evidence for toxicity concerns are both discussed. Current UK guidelines recommend $400 \mathrm{IU}$ of vitamin D per day whereas 6,000-10,000 IU per day is required to maintain blood levels of $40 \mathrm{ng} / \mathrm{ml}$, widely accepted as being the level required to support immunity, optimal health, and reduction in all-cause mortality. The financial cost of vitamin D deficiency in the UK has been estimated at around $\mathrm{f} 20$ billion per annum.

\section{Introduction to Vitamin D}

Vitamin D3 (cholecalciferol), a fat-soluble vitamin, is made by the action of UVB sunlight on 7dehydrocholesterol in the skin and converted in the liver to $25(\mathrm{OH}) \mathrm{D}$ or 25 -hydroxyvitamin $\mathrm{D}$, occasionally referred to as calcidiol. This is the form that circulates in the blood at detectable levels and measured in order to determine serum vitamin $D$ status. The kidneys carry out a second hydroxylation by the enzyme 1- $\alpha$-hydroxylase to convert $25(\mathrm{OH}) \mathrm{D}$ to $1,25(\mathrm{OH}) \mathrm{D}$ or 1,25 -dihydroxyvitamin $D$, also referred to as calcitriol or active vitamin $D$ [17]. This second hydroxylation to make the active form, calcitriol, has also been found to occur in many other cells including those in the respiratory tract epithelia and cells involved in the immune response. Calcitriol is 1000 times as potent as the inactive circulating $25(\mathrm{OH}) \mathrm{D}$ form but there is around 1,000 times less of it. Please note that, except where otherwise stated, the term vitamin $D$ has been used interchangeably throughout to refer to any of the three forms. 
The calcitriol form of vitamin $D$ functions as a hormone in every cell of the body, all of which have vitamin $\mathrm{D}$ receptors (VDR). VDRs are nuclear transcription factors that epigenetically control the expression of up to 2,000 different genes including almost 300 genes just in white blood cells involved in the immune response [79]. There is no doubt that Vitamin $D$ is of critical importance to many aspects of health. In addition to its long-known role in bone health, it also plays an important and central role in immune-enhancement and immune-modulation.

A note regarding units: $\mathrm{ng} / \mathrm{ml}$ has been used throughout for serum levels of vitamin $\mathrm{D}$. To convert $\mathrm{ng} / \mathrm{ml}$ of $25(\mathrm{OH}) \mathrm{D}$ to $\mathrm{nmol} / \mathrm{l}$ the conversion factor is 2.5 .

\section{How Widespread is Vitamin D Deficiency?}

\subsection{Vitamin D Deficiency in BAME Populations v White Caucasians}

It is generally acknowledged that BAME populations in the west are vitamin D deficient because the screening effect of melanin pigment in darker skin means far stronger sunlight is required to make vitamin D from sun exposure [17]. Although a serum level of $20 \mathrm{ng} / \mathrm{ml}$ is generally accepted as the level necessary to prevent deficiency (and resultant conditions such as rickets, osteoporosis and osteomalacia), it is thought by many experts in this field that a far higher level of $40-60 \mathrm{ng} / \mathrm{ml}$ or more is required to achieve optimum immune system and cancer fighting capability, with $30 \mathrm{ng} / \mathrm{ml}$ being "sufficient" but not optimal $[13,52,74] .40-60 \mathrm{ng} / \mathrm{ml}$ is also the level required to achieve normalised parathyroid function [3-10] and also the level maintained by indigenous peoples such as the Maasai despite their very dark skin $[61,62]$

Darker skins cannot make enough vitamin $D$ at latitudes above the $37^{\text {th }}$ parallel even in summer and even white skins cannot make vitamin D in the winter months when the UVB light is much weaker [4$6,17]$. Furthermore, studies have found that men generally have lower vitamin $D$ levels than women [70].

The following is a table produced by Grassroots Health, USA showing rates of deficiency and sufficiency in different ethnic groups in the US [11]. The differences are very striking; Only $6 \%$ of black ethnic groups have optimal vitamin D levels of $40 \mathrm{ng} / \mathrm{ml}$ but surprisingly, only between $15-20 \%$ of white skinned individuals attain this level. The most dramatic difference is that whilst only around $15 \%$ of the white population is deficient, meaning they have levels below $20 \mathrm{ng} / \mathrm{ml}$, between $55-60 \%$ of the black ethnic population is deficient. The vitamin D status of Asians, Hispanics and others lie in between these extremes. 


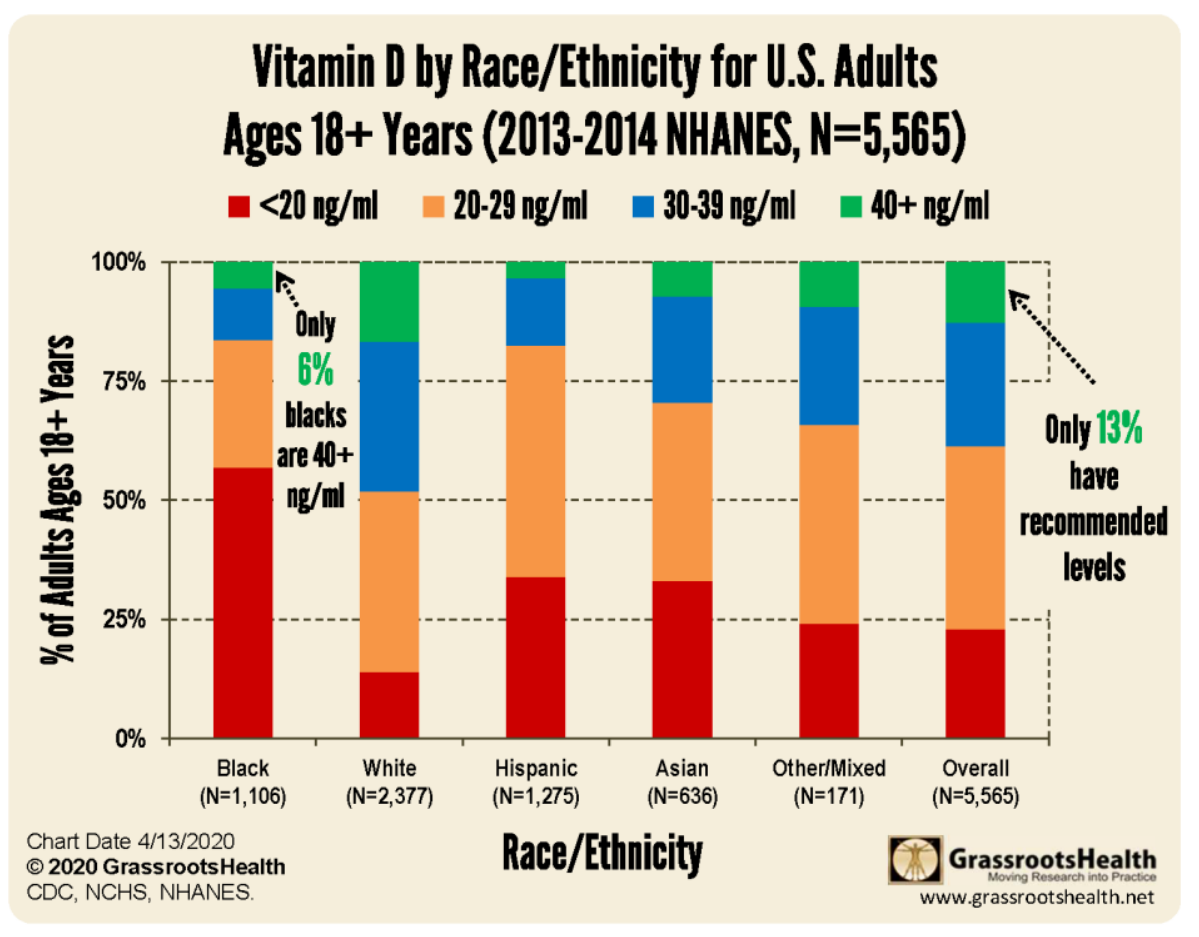

This demonstrates that vitamin $D$ deficiency is not just an issue affecting black/dark skinned individuals but is far more widespread, with many who are white skinned also suffering from vitamin D insufficiency and less that $20 \%$ of them achieving optimal serum levels of at least $40 \mathrm{ng} / \mathrm{ml}$.

\subsection{Vitamin D Deficiency in the UK and Europe}

The above statistics, as noted, are from the US, and it may be expected that the situation is better in the UK. Unfortunately, it appears to be surprisingly worse.

The following is a comparison of deficiency rates for different European countries rounded to the nearest whole number. Although the data is taken from different studies collated in a 2019 study by Paul Lips using different population sets [12], it can nevertheless provide some useful comparisons. Where there are two studies relating to one country, the average values have been used (as the two figures were generally close), rather than a weighted average. No statistics were provided for Spain.

Average Vitamin D levels and rates of deficiency by country

\begin{tabular}{|l|l|l|l|}
\hline Country & Average ng/ml & $\mathbf{\%}<\mathbf{1 0 n g} / \mathbf{m l}$ & $\mathbf{\%}<\mathbf{2 0 n g} / \mathbf{m l}$ \\
\hline Norway & 27 & 0 & 17 \\
\hline Sweden & 29 & 0 & 16 \\
\hline Iceland & 23 & 4 & 34 \\
\hline Denmark & 26 & 0 & 24 \\
\hline Germany & 21 & 5 & 50 \\
\hline UK & 19 & 15 & 56 \\
\hline N Ireland & unavailable & 17 & 66 \\
\hline Ireland & 23 & 6 & 45 \\
\hline Belgium & 20 & 8 & 51 \\
\hline Netherlands & 27 & 4 & 31 \\
\hline France & 24 & 6 & 35 \\
\hline Greece & 20 & 2 & 51 \\
\hline Italy & 24 & unavailable & 52 \\
\hline
\end{tabular}


The table shows a startling level of vitamin D deficiency in the UK and N Ireland; $56.4 \%$ and $66.2 \%$ of the population have levels below $20 \mathrm{ng} / \mathrm{ml}$; similar to that seen in the American black population in the table above. This makes the UK the most deficient country in the table with average blood levels of vitamin D of $19 \mathrm{ng} / \mathrm{ml}$, followed closely by Belgium with $19.7 \mathrm{ng} / \mathrm{ml}$. However, no other country comes near the UK for severe deficiency; the percentage of the population with levels below $10 \mathrm{ng} / \mathrm{ml}$ is over $15 \%$, with Belgium again in second place with $7.3 \%$.

In addition to the disproportionate number of COVID-19 related deaths in the BAME communities in the UK, it is of note that the Somali population of Sweden has also suffered a disproportionate number of deaths: despite comprising less than $1 \%$ of the population, press reports as at 11 May state that they accounted for $18 \%$ of COVID-19 related deaths countrywide and $40 \%$ of Stockholm's COVID-19 related deaths.

Generally, however, vitamin D status in Scandinavian countries is, given their latitude, surprisingly better than southern European countries. This is thought to be the result of widespread awareness of the issue, food fortification having been in place for many years, and a far higher consumption of vitamin $D$ containing oily fish and fats [82]. It is interesting that as a result of a review by the independent Swedish Council on Health Technology Assessments of 16,000 studies through May 2013, the Swedish were advised to consume plentiful quantities of animal fats and cream and to eliminate/reduce sugar and carbohydrates as a strategy to prevent diabetes, cardiovascular disease, and obesity. Meanwhile, in contrast, nutritional advice in the UK has been geared strongly towards a low animal fat diet.

\subsection{Vitamin D Deficiency Elsewhere}

Even in hot, sunny countries, vitamin D deficiency can still be rife because of full clothing and deliberate sun avoidance for cultural reasons, e.g. in some parts of the Middle East and in certain socio-economic groups in India. Rural and slum dwellers possibly achieve higher levels of sun exposure and therefore better vitamin $D$ levels. The percentage of the population with $<20 \mathrm{ng} / \mathrm{ml}$ in India and the Middle East is remarkably high, $75 \%$, and $90 \%$, respectively, compared to the USA, Australia, and Canada: $36 \%, 31 \%$ and $61 \%[12,13]$.

\subsection{What Other Categories of People Might be Vitamin D Deficient?}

What is perhaps not generally known is that the obese, another high-risk group, are also highly likely to be highly vitamin $D$ deficient as they require 2-5 times (or even more) vitamin $D$ than others, dependent on the level of obesity $[4,9,17,52,78]$. Unless they are taking exceptionally high levels of supplements they are highly likely to be even more deficient than BAME categories. The fat-soluble vitamin is thought to become trapped in fat cells although the exact biochemistry of this is uncertain. The elderly is another category highly likely to be vitamin $D$ deficient unless they supplement; older skin gradually loses the ability (by up to $75 \%$ ) to convert 7-dehydrocholesterol to vitamin $D[4,9,17]$.

It is also of note that virtually all of the other remaining categories that have an increased risk from COVID-19 are also likely to have a high level of vitamin D deficiency. Other health conditions well documented in a vast body of medical literature, including interventional studies, shown to be caused by (and not merely associated with) lack of optimal vitamin $D$ include: 
-asthma, allergic rhinitis, and other respiratory diseases[30-31] - autoimmune diseases[17,22,74,75]

-high blood pressure [14-17]

- dermatological conditions [3,9]

-heart disease $[17,55,89]$

- fatigue (often misdiagnosed as fibromyalgia) [17]

- bone loss $[3,12,13,17]$

- bone and back pain $[3,9,12]$

- depression [3,9]

-obstructive sleep apnoea

- nasal polyps

- diabetes [13,18-21]

- hair loss

- muscle pain $[3,9]$

- infertility $[3,9,12]$

-acute respiratory infection [36-52]

- Otis media

- chronic rhinosinusitis

- cancer (including breast, melanoma, ovarian, prostrate, head and neck, Hodgkin's, and nonHodgkin's lymphoma) [23-28]

-Alzheimer's

Unconverted vitamin $\mathrm{D}$, rather than the $25(\mathrm{OH}) \mathrm{D}$ form has been shown to stall the progression of prostate cancer at high concentrations [28].

Although there may also be other factors involved in the above conditions, such as various nutrient deficiencies and the metabolism of excessive quantities of glucose, vitamin $D$ deficiency is a major contributory factor in the genesis of these conditions. Although high serum vitamin $D$ levels could have prevented their onset, subsequent supplementation may or may not be effective in alleviating a condition once it has become established, depending on the nature of the particular conditions.

Despite this, there is still every expectation that increasing the serum levels of vitamin $D$ for people with these conditions, all of whom are highly likely to be vitamin D deficient, can help combat viral infection as this involves different biological mechanisms as illustrated in Section 5 below.

It is of interest that some pharmaceutical drugs including some antihypertensives, antibiotics, antiepileptics and anti-inflammatory agents used to treat some of these conditions can reduce serum vitamin $D$, exacerbating existing vitamin D deficiency [67].

\section{Connection Between Vitamin D Deficiency and Respiratory Tract Infections} [36-52]

Multiple cross-sectional studies and interventional studies have associated lower vitamin D levels with a statistically significant increase in rates of infection with respiratory viruses including influenza [42$52]$.

A recent paper, William B. Grant et al "Evidence that Vitamin D Supplementation Could Reduce Risk of Influenza and COVID-19 Infections and Deaths" April 2020: https://www.grassrootshealth.net/wpcontent/uploads/2020/04/Grant-GRH-Covid-paper-2020.pdf discusses the sizeable body of compelling literature evidencing the role of vitamin $\mathrm{D}$ in preventing respiratory illnesses, and also suggests possible reasons why no association was found in others.

In addition, Dr Rachel Neal who is currently leading the world's second largest trial of high dose vitamin D supplementation, reported that a study of 78,000 patients last year found that patients with low levels of vitamin $D$ were twice as likely to develop acute respiratory infections and be sicker for longer that patients with high vitamin D levels [81].

In another study described by Dr Holick, it was demonstrated that supplementing one group of postmenopausal women with 2,000 IU of vitamin D resulted in a $90 \%$ reduction in upper respiratory tract infections compared with a group receiving only $400 \mathrm{IU}$ [73p112]. Note that $400 \mathrm{IU}$ is the level 
currently recommended by Public Health England. In another study, vitamin D blood levels of at least $38 \mathrm{ng} / \mathrm{ml}$ were associated with a two-fold reduction in the risk of developing acute respiratory tract infections [52]. In contrast, as already noted, the average serum level for the UK is only $19 \mathrm{ng} / \mathrm{ml}$.

Although the 1918 Spanish flu is not examined further here it may be of interest that the sunnier US states such as Texas were observed to have had lower death rates than the Northeast.

The seasonality of flu very probably has little to do with the premise that viruses degrade in the heat (which needs far higher temperatures than our UK summers) but more to do with the fact that we rely on sunlight for a high proportion of our vitamin D requirements. Any reserves of vitamin $D$ made in the summer months, meagre as they are, are depleted from September onwards so that by December/January, serum levels become perilously deficient in many.

\section{The Critical Role of Vitamin D in the Immunological Response to a COVID- 19 Infection}

\subsection{Vitamin D in the Innate and Adaptive Immune Response}

The following discussion is limited to the known biological role of vitamin $D$ in the type of immune responses seen against a SARS type respiratory infection and is by necessity a simplified account, ignoring the involvement of many other immune cells and chemical signals within multiple complex, interactive, cross regulating systems of immune responses.

VDR's (vitamin D receptors) are abundant in cells involved in the immune response, i.e. macrophages, neutrophils, T lymphocytes (Th1 and Th2) and many others [22,67]. Vitamin D clearly has an important role to play in these cells. It is noteworthy that apart from the kidneys, other locations where the enzyme, 1- $\alpha$ - hydroxylase, (which converts vitamin $D$ into its active form), occurs, are the lung epithelial cells, vascular epithelia, gut epithelia and numerous cells involved in the immune function[22,67].

On detecting a foreign pathogen via toll-like receptors (TLR's), the transcription of the immune system's antivirals, human cathelicidin and defensins (which also have fungicidal and bactericidal properties), is rapidly increased in monocytes, neutrophils and in other immune cells of the innate immune system in lung, epithelia, intestine and other surfaces which form an interface with the external environment. This forms part of the first line of defence against invading pathogens. This upregulation in antiviral production has been shown to be highly dependent on sufficient vitamin $D$ [32-38]. In a particularly interesting study, it was observed by researchers that sera from African Americans who are known to have low blood levels of vitamin $D$ was inefficient in inducing production of cathelicidin. When the researchers supplemented the sera with $25(\mathrm{OH}) \mathrm{D}$, cathelicidin levels increased to the same levels seen in white Americans [ 38].

Vitamin D also increases the phagocytic killing ability of immune cells such as natural killer cells, macrophages and neutrophils and reinforces the physical barriers of epithelial cells by maintaining tight junctions [22]. These first line defences of the innate immune system can be highly effective in limiting or preventing progression of infection at an early stage, resulting in no symptoms (asymptomatic) or only mild symptoms: it is clear that this stage is highly dependent on vitamin D 
status. As discussed at Section 5.3, prior infection with pathogens expressing cross-reacting antigens can also result in asymptomatic or mild cases.

In critical cases of COVID-19, many inflammatory cytokines become significantly elevated. It has been confirmed that interferon- $\gamma$, and both Th17 and TH1 cells which highly express inflammatory cytokines, are all involved in acute lung injury during the late phase of SARS infection $[84,85,86]$. Vitamin D has been shown to inhibit Th17 pro-inflammatory cytokines [87] and Th1 cytokines ( IL-2 and IL-17, IL-6, IL-1 $\beta$ and interferon- $\gamma$, etc) by suppressing production of angiotensin II (see further below), but increase expression of anti-inflammatory Th2 cytokines by macrophages. Induction of T regulatory cells by the action of vitamin $D$ further suppresses the inflammatory response $[22,67]$. Vitamin $D$ deficiency therefore unbalances the immune response by allowing the unchecked dominance of the pro-inflammatory cytokines to create the type of uncontrolled cytokine storms which directly impact the respiratory system, resulting in damage and vascular permeability, as seen with some COVID-19 deaths. In some, ARDS (acute respiratory distress syndrome) can be a potentially disastrous outcome [39-41].

Vitamin D upregulates expression of VDRs and ACE2 (angiotensin converting enzyme 2) which has been shown to be protective against acute lung injury [40]. As part of the RAS (renin-angiotensin) system, ACE2 is critical in suppression of the angiotensin II induced inflammatory pathways. It does this by converting angiotensin II to anti-inflammatory angiotensin A(1-7). Meanwhile, in a double manoeuvre, the upregulated VDR blocks transcription of renin, an enzyme required to produce angiotensin 1, an intermediary of angiotensin II, thus depressing levels of angiotensin II further $[40,41]$. However, as SARS viruses also dock at ACE2 receptor sites, the up regulation of ACE2 (which is dependent on vitamin $D$ as noted above,) is critical in preventing a cascade of inflammation. If SARS blocks sufficient ACE2 and upregulation is insufficient, inflammation cannot be effectively controlled. Either insufficiency of vitamin $D$, a very high viral count, or an immune system which has been previously mis-programmed towards a skewed immune response, away from the anti-inflammatory and towards the inflammatory state (the factors precipitating mis-programming being outside the scope of this analysis), can all potentially result in a SARS type virus gaining the upper hand, before or while antibodies are being produced.

In addition, apparently uniquely in COVID-19 cases, the virus has an effect on red blood cells, precipitating breakdown of haemoglobin, thereby preventing red blood cells from carrying oxygen. This leads to dangerously low levels of oxygen, or hypoxia, which cannot be resolved by ventilators, and the formation of blood clots which further impede airways. It is of interest here that a number of studies demonstrate the anticoagulant effects of vitamin D [72 and references therein] and link lack of vitamin D to increased blood clotting and DVT (deep vein thrombosis). Vitamin D induced suppression of inflammatory cytokines include those cytokines involved in clot formation e.g. IL-22 which upregulates fibrinogen formation [87]. Therapeutic use of vitamin D to dissolve blood clots in DVT patients has been proposed [72], although if a patient has optimal levels of vitamin D to begin with, given the evidence so far presented in this review, they may never get as far as this dangerous stage.

Given the descriptions in this section, the strength of response of the innate immune system's first line defence system, which is highly dependent on vitamin D status, is potentially of far greater importance that in a non-SARS, non-COVID-19 respiratory infection as that would determine whether the infection proceeds any further. Whilst the innate response happens within hours, the adaptive immune response, the arm of the immune system that produces antibodies, is slower to respond. It is well established that the antibody response can take 5-7 days to come into play. 
In the adaptive immune response, vitamin $\mathrm{D}$ acts as an immune modulator; antigen presenting cells and $T$ and $B$ lymphocytes involved in antibody production against pathogens are prevented from being over expressed by the presence of sufficient levels of vitamin $D$, thus preventing the type of hyperstimulation which can trigger autoimmunity $[22,74,75]$. Lack of sufficient vitamin $D$ has been implicated in many auto-immune disorders such as lupus, Sjogren's and others [17].

Vitamin D also upregulates the expression of glutathione, the human body's antioxidant which also acts as an antiviral and reduces the inflammatory response [83].

Vitamin $D$ is therefore critical for a rapid, effective but balanced and controlled immune response which does not result in overactivity and autoimmunity.

5.2 Gender Differences: Major genes coding for innate immunity are located on the X-chromosome. Women therefore have two copies and men, one. The interaction of these genes together with their generally higher vitamin $D$ status as well as hormonal factors are thought to result in women being less adversely affected by COVID-19 and by all infections generally than men [68-70].

5.3 Asymptomatic and Mild Cases: It has already been demonstrated that a strong innate response underpinned by optimal vitamin D status can be successful in halting progression of infection. This is what very probably happens in many of these cases. There is also another quite significant category of people that are likely to already have some immunity to SARS-CoV-2 despite never having encountered it before. Recent research, detailed below, testing blood samples including blood from 2015-2018 blood banks has demonstrated that between $34 \%$, and $50 \%$ of people have T-helper cells that cross-react with SARS-CoV-2 antigens from the spike protein and also with non-spike proteins. These are also present in people who have actually had COVID-19 but in those that have not, the authors presume they were acquired through prior infections with one of the 4 common cold coronaviruses. However, no follow up studies have been carried out to demonstrate that these people will have mild, less severe or no symptoms when they encounter SARS-CoV-2.

Immunologist Andreas Thiel's research at Charite University Hospital, Berlin: https://www.medrxiv.org/content/10.1101/2020.04.17.20061440v1

Immunologists Shane Crotty and Allessandro Sette's research at La Jolla Institute for Immunology: https://www.cell.com/cell/fulltext/S0092-8674(20)30610-3

Helper T-cells such as those in these studies take messages to antibody producing B cells, stimulating them to upregulate production of antibodies. They also stimulate killer T-cells to kill pathogens and send signals to memory $T$-cells which are thought to retain long lasting immune memory. The correct balanced expression of such T-cells is also controlled by vitamin D [75].

5.4 Children have less developed and less specialised adaptive immunity and are more dependent on their innate immune response. The maturing immune system is also primed towards an antiinflammatory response ${ }^{1}$. In addition, they tend to have greater sun exposure and therefore higher vitamin D levels. They also have greater exposure to dirt and a higher level of interaction with microorganisms in the general environment, all of which re-enforce and strengthen the innate immune response and play a critical role in maturation of the developing adaptive immune system. The

\footnotetext{
${ }^{1}$ Kawasaki like cases: In a very small number of cases, it is theorised in this report that past toxins or environmental assaults, perhaps while in a low vitamin D state may re-programme the immune responses so that it becomes skewed towards an inflammatory response. It is possible that in rare cases, a later encounter of such a pre-primed immune system with a virus can then tip the system into abnormal uncontrolled inflammation.
} 
stronger innate and anti-inflammatory response might be reasons why children are far less affected and are mostly asymptomatic.

It should be noted that despite becoming immune following a COVID-19 infection, it is possible that young children might not produce much in the way of specific antibodies which can be detectible in a COVID-19 antibody test. Antibodies in children can be broad spectrum rather than highly specific, capable of dealing with a more varied range of antigens [76]. Immune memory can also reside in Tcells as noted above, and further research is required in order to establish exactly where immune memory resides in young children.

\section{New Evidence linking COVID-19 Related Deaths to Vitamin D Deficiency}

\subsection{Connections and Correlation Studies}

A recent study of 20 European countries by Queen Elizabeth Hospital Foundation Trust found a correlation between level of vitamin D deficiency and COVID-19 related deaths and cases. https://link.springer.com/article/10.1007/s40520-020-01570-8

The data for this has been taken from the same source as the table in section 3.2. These are interesting findings, although they may be slightly limited by the fact that countries are at different stages in the infection curve and the criteria used to classify a death as being COVID-19 related may differ in different countries. More significantly, the death rates reported will be dependent on the level of testing in each country until antibody testing establishes the true extent of infection and therefore the true death rate per million of population. However, those factors are true for all country comparisons and it will be very interesting to see if the correlation still holds when more directly comparable data becomes available for all the countries in the study.

It is, however, of note that the UK and Belgium, the very two countries that have the highest levels of vitamin D deficiency (Section 3.2 ) are also those with very high numbers of COVID-19 related deaths per million of population.

A recently published pre-print of research by Northwestern University analysing data from 10 countries found a strong correlation between low vitamin D levels and cytokine storms in COVID-19 patients as well as a correlation between vitamin $D$ deficiency and mortality: https://www.medrxiv.org/content/10.1101/2020.04.08.20058578v4, with commentary by the researchers at: https://www.sciencedaily.com/releases/2020/05/200507121353.htm

Recent Irish research published by Trinity College, Dublin, the TILDA study, https://tilda.tcd.ie/publications/reports/pdf/Report Covid19VitaminD.pdf

, also supports the premise that vitamin D deficiency is widespread and is likely to be a major factor in poor outcomes from COVID-19.

Another point of interest is that UVB light required to make vitamin $D$ is blocked very effectively by air pollution. Northern Italy and Wuhan where COVID-19 related death rates were much higher than elsewhere are both known to suffer from particularly poor air quality. Whilst air pollution is thought to be a factor in the very high death rates in these two areas, lack of vitamin D may have compounded this effect.

It is also of note that sunny countries where sun avoidance is not common, for example, most African countries, Australia, Thailand, Sri Lanka, Hong Kong, South Korea, the Caribbean, and many countries around the equator appear to have escaped with very few deaths, Brazil being a notable exception. 


\subsection{Direct Evidence for Vitamin D Deficiency in COVID-19 Related Deaths}

We now have direct evidence linking deaths and critical outcomes to COVID-19 related deaths from studies yet to be peer reviewed. This following graph from Grassroots Health summarise the results of a small study from the Philippines [11]. It illustrates that only $4 \%$ of those who had vitamin D blood levels above $30 \mathrm{ng} / \mathrm{ml}$ became critically or severely ill, whilst $96 \%$ of those whose levels were below $30 \mathrm{ng} / \mathrm{ml}$ became critically or severely ill. $96 \%$ of mild cases were found to have sufficient, $>30 \mathrm{ng} / \mathrm{ml}$, blood levels of vitamin D. The researchers did not look at optimal levels above $40 \mathrm{ng} / \mathrm{ml}$.

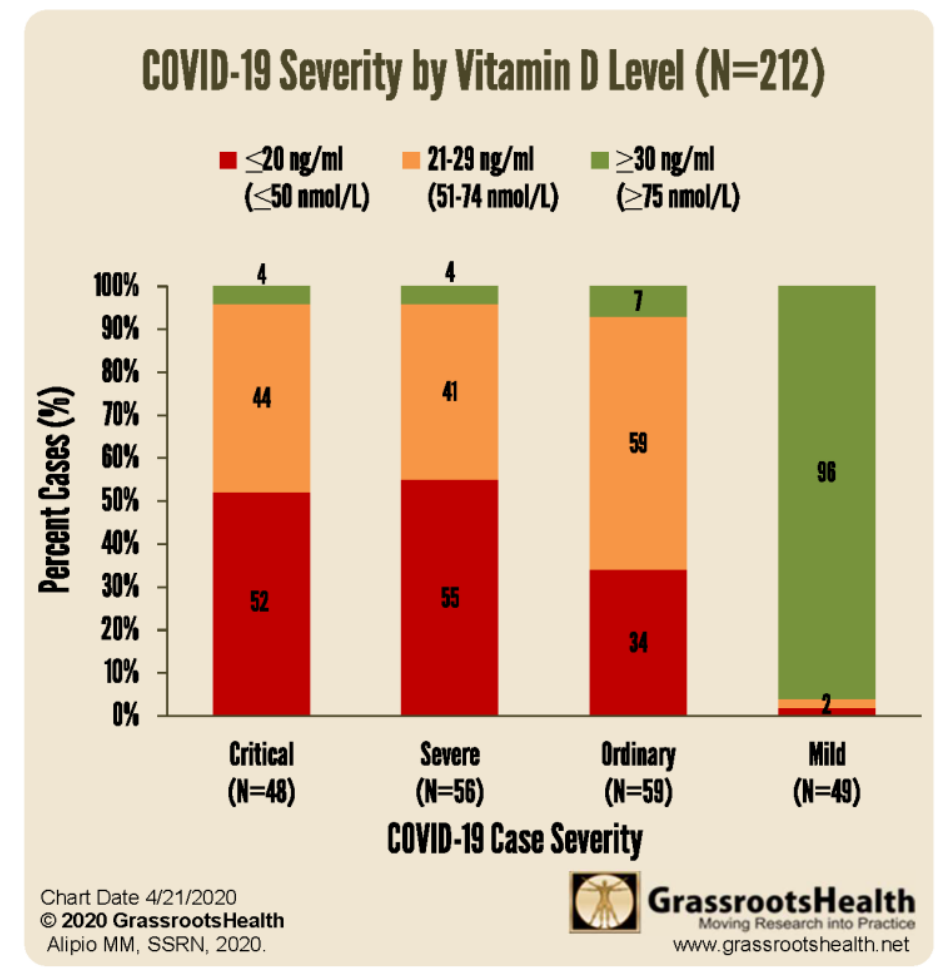

Indonesian research published more recently and updated on 6 May using data from 780 patients who had tested positive for COVID-19 [71] have confirmed these findings. While only $4 \%$ of patients with sufficient levels of vitamin $\mathrm{D}(>30 \mathrm{ng} / \mathrm{ml}(\mathrm{OH}) \mathrm{D})$ died, the mortality rate was $87.8 \%$ and $98.9 \%$ in the insufficient $(20-30 \mathrm{ng} / \mathrm{ml})$ and deficient $\quad(<20 \mathrm{ng} / \mathrm{ml}) \quad$ groups, respectively. After adjusting for confounding factors such as age, comorbidities and sex, the researchers still found that death was 7.63 times as likely in the insufficient group and 10.12 times as likely in the deficient group.

These are highly interesting findings, and if taken in isolation, the question of whether deficiency led to the poor outcomes or whether the poor outcomes depleted serum vitamin $\mathrm{D}$ might well be a legitimate one. It is acknowledged that vitamin $\mathrm{D}$ may well become depleted during the course of an infection, perhaps more so in the critically ill. However, to argue for the second alternative scenario would require a narrowly focused dismissal of all the other evidence and facts noted in this report.

On the contrary, when taken together with the large body of interventional studies on respiratory infections, the biochemical mechanisms outlined above which illustrate strong biological plausibility, the correlations between countries discussed above, and the knowledge that high risk groups are almost certain to be vitamin $D$ deficient to begin with, the results of these latest studies point strongly to the conclusion that there is a compelling case implicating vitamin D deficiency in COVID-19 outcomes and deaths.

\section{Cautions Regarding Trial Design and Explanation of Negative Findings}

If larger scale UK specific interventional studies are conducted to confirm the above findings there is an important word of caution. This is that because, quite unlike other nutrient interventional studies where one group receives a supplement and the control group receives a placebo, it is quite possible for the control group to end up with higher vitamin D levels because of sun exposure, rendering the 
comparisons between the groups and therefore the test results meaningless. Hence, it is critical that regular blood tests of serum 25(OH)D levels are carried out at appropriate intervals during the test period to ensure that the test group does in fact have significantly higher blood levels of vitamin $D$ than the controls. Dosing of the test group should also be daily (see below) with D3, not D2 [63,64].

Vitamin D increases calcium absorption: therefore, calcium supplements should not be taken in excess at the same time. If there is a concern about osteoporosis, it is of note that countries with the highest calcium intakes have some of the highest rates of osteoporosis. What is required to build bone density is often not more calcium, of which most of us obtain adequate amounts in our diets, but sufficient vitamin D3, K2 and magnesium, all of which many are far more likely to be deficient in.

Most studies that found vitamin D unhelpful used either; far too low a dose; a weekly or monthly dose rather than a daily dose; D2 not D3; a single extraordinarily high dose (eg.100,000 IU or greater bolus dose); or did not ensure that blood levels of vitamin $D$ were much higher than those of the controls or sufficiently high i.e. above $40 \mathrm{ng} / \mathrm{ml}[53,54]$. In others, lack of other limiting vitamin and minerals such as magnesium and $\mathrm{K} 2$ may also have been a factor [58-60] and therefore the status of these also needs be determined in any rigorous vitamin $\mathrm{D}$ trial.

Magnesium is required for the conversion of vitamin $D$ to its active form, calcitriol $[59,60]$. As a high proportion of the UK population is magnesium deficient, supplementation with magnesium may also be required to gain the benefits of optimal vitamin D3. In addition, vitamin $A$ and $D$ work together and the levels of vitamin A must also be adequate. Vitamin K2 may also need to be supplemented in most people as it has been shown to work with vitamin $D$ to keep calcium out of arteries and hence reduce coronary heart disease (,as well as to pull calcium into bones) [58] and this is a nutrient that many people are deficient in.

\section{Daily Requirements and Concerns Regarding Toxicity and Sun Exposure}

It is preferable to obtain vitamin $D$ from sensible sun exposure than supplements as the half-life in the body is 2-3 weeks for supplements but double that for vitamin D produced in the skin. Vitamin D produced by the action of sunlight is stored in subcutaneous fat cells under the skin which release it gradually [73 p147].

In the UK, average blood levels are just $19 \mathrm{ng} / \mathrm{ml}$, under half the minimum optimal level. Whilst the daily dose suggested by Public Health England of $400 \mathrm{IU} / 10 \mathrm{mcg}$ may be adequate to ward off the effects of severe deficiency which results in rickets, it has been demonstrated to be far too low to achieve blood levels of $40-60 \mathrm{ng} / \mathrm{ml} 25(\mathrm{OH})$ vitamin $\mathrm{D}$, consistent with an optimal balanced immune function and the prevention of many other diseases. Even 2,000 IU daily has been shown to only achieve serum levels of $30 \mathrm{ng} / \mathrm{ml}[80]$.

Studies show that almost 6,000-10,000 IU per day is required to maintain optimal blood levels of $40 \mathrm{ng} / \mathrm{ml}$ levels $[5,80]$. This can come from a combination of food, light, and supplements. However, as winter UVB light in the UK is not sufficiently strong to make vitamin D, 6,000-10,000 IU is required from food and supplements from September to April if optimal levels are to be maintained over the winter. In practical terms this means supplementing a significant proportion of this as very little can be derived from the diet. The darker the skin, the higher the amounts needed from supplementation in summer. Requirements depend on body mass and the obese may require double or triple the average amounts. 
In summer, at UK latitudes, white skinned individuals following the recommended sunlight exposure of 15 minutes 3 times a week and wearing shorts and t-shirt were found to achieve blood levels of vitamin $\mathrm{D}, 25(\mathrm{OH})$ D of less than $20 \mathrm{ng} / \mathrm{ml}$, only enough vitamin $D$ to prevent rickets [88]. They did not achieve optimal $(40-60 \mathrm{ng} / \mathrm{ml})$ or even sufficient $(30 \mathrm{ng} / \mathrm{ml})$ levels. Therefore, even the white skinned population needs to top up with supplements throughout the summer unless they achieve especially good sun exposure. Even in summer the UVB rays are not strong enough to make much vitamin D before around 10 am or after around 3pm [17].

A white-skinned individual in a bathing suit can make 20,000 IU in 20-25 minutes of sun exposure in high summer [17] at UK latitudes. Synthesis is self-limiting: continued sun exposure does not result in continued synthesis beyond around 25,000 IU. The amount of UVB required to achieve this, $54 \mathrm{~mJ} / \mathrm{cm}^{2}$, is termed 1 minimal erythemal dose or MED. It is extremely difficult for a dark-skinned individual to achieve any appreciable increase in their vitamin D levels from sun exposure in the UK. As an illustration, a fair white-skinned person exposed to 1 MED can achieve a 50-fold increase in serum vitamin $D$, but a very dark-skinned person of the same age shows no significant increase after the same exposure. In contrast they would need 5-10 times 1 MED merely to make $60 \%$ of the same level [17]. As around $90 \%$ of our requirements need to come from sun exposure or supplements (,given food can only provide a small fraction of it) [17], it is clear that BAME populations in the UK are far more reliant on supplements to meet their vitamin $D$ needs. Further, it is clear that with only $400 I U$ per day they will not achieve even a sufficient level.

Given the body's capacity to make the equivalent of up to 25,000 IU per day, suggestions that levels above 2,000-4,000 IU may be toxic are unfounded. Daily doses of 10,000 IU [8] and even 30,000 IU [65] have been firmly demonstrated to be perfectly safe $[65,61,62,66]$. Toxicity is extremely rare and a review of 15 studies show that toxicity is not seen until blood levels reach above $200 \mathrm{ng} / \mathrm{ml}$ [65]. To put that into context, lifeguards are known to maintain blood levels of above $100 \mathrm{ng} / \mathrm{ml}$ without ill effects $[9,17,61,62]$. The European Food Safety Panel's Statement of Scientific Opinion acknowledges that no adverse effects have been observed at $10,000 \mathrm{IU}$ or $250 \mathrm{mcg}$ per day [8]. People with impaired kidney function should be closely monitored and remain under the guidance of a medical professional.

Concerns about cancer dangers from sun exposure may be misconstrued. Almost $90 \%$ of skin cancer deaths are caused by melanoma. Although there is an association between excessive sun exposure and non-melanoma skin cancers, and excessive sun exposure or burning should be avoided, there is no credible scientific evidence that moderate sun exposure can cause melanoma[17,77,61,62].. Working indoors and lack of vitamin $D$ is associated with a significantly increased risk of melanoma while occupational sun exposure is associated with reduced risk of melanoma [77]. Melanoma is more often found in areas which are not exposed to the sun $[17,62]$. There are other risk factors for melanoma such as being obese, high alcohol consumption and being sunburnt when young, but sun exposure in the present which is no more than moderate is not a risk factor. Ironically, $83 \%$ of Australian dermatologists were found to be vitamin D deficient [29].

The dangers and extensive ill effects on health of a lack of moderate sun exposure and consequential lack of vitamin $D$, appears to, by far, outweigh any health benefit from avoiding it. It is possible that sun exposure may have other unknown positive effects on the human body besides making vitamin D. A Swedish 20 year follow up study of almost 30,000 women found that avoidance of sun exposure is a risk factor for death of similar magnitude as smoking! [89]. 


\section{Conclusion}

It is clear that the existing medical literature on the crucial role of vitamin $D$ in fighting respiratory infections and controlling overactivity of the immune system, is abundant and highly persuasive. There is new evidence that maintaining high vitamin $D$ serum levels is highly protective against COVID-19. Furthermore, studies have already established deficiency in a higher proportion of the UK population than in other European countries or the US. The UK population has remained largely vitamin D "deficient" and "insufficient" with average blood levels of only $19 \mathrm{ng} / \mathrm{ml}$, far lower than levels of 40 $60 \mathrm{ng} / \mathrm{ml}$ shown to support good health and resistance to infection.

Whilst the daily dose suggested by Public Health England of $400 \mathrm{IU} / 10 \mathrm{mcg}$ may be adequate to ward off the effects of severe deficiency which results in rickets, it is far too low to achieve blood levels of $40-60 \mathrm{ng} / \mathrm{ml} 25(\mathrm{OH})$ vitamin D consistent with optimal immune function. Studies show that 6,000 to $10,000 \mathrm{IU}$ or up to $250 \mathrm{mcg}$ per day, up to 20 times the current recommendation is required from a combination of sources, to maintain blood levels of $40 \mathrm{ng} / \mathrm{ml}$ levels $[5,80]$.

It is recommended that GP testing of blood levels of vitamin D and high levels supplementation is implemented immediately for all in BAME, the obese and other high-risk categories. As a cost-effective intervention with little to lose, low risk of toxicity (Section 8 ) and much to be gained, if efforts are made to raise vitamin D levels, it is likely that the UK will see a lower death rate going forward from COVID-19 and bolster itself against any influenza epidemics or other future pandemics.

Large-scale testing of vitamin D status of COVID-19 patients in UK hospitals and interventional studies may be desirable to gain UK specific information to further inform supplementation guidelines and policy. To avoid a false negative result from trials however, it is critical that for reasons discussed in Section 7, dosing is daily, blood levels of vitamin D are measured at appropriate intervals and the target group's level is raised to at least $40 \mathrm{ng} / \mathrm{ml}$.

All-cause mortality has also been shown in a number of studies to be inversely related to serum vitamin D levels $[55-57,89]$. Many conditions associated with vitamin D deficiency have already been mentioned but that list is by no means exhaustive. Vitamin D deficiency in pregnancy not only has implications for the mother's own health but will also cause the unborn child to be epigenetically "imprinted" to be susceptible to chronic disease in later life. A panel of prominent researchers in the field attempted to evaluate the total cost of vitamin D deficiency in western Europe, publishing a paper in 2009 which concluded that raising the population's vitamin D levels to $40 \mathrm{ng} / \mathrm{ml}$ could result in savings on a conservative basis, of $€ 187$ billion [74]. This translates into an estimated potential saving of around $£ 23$ billion per annum for the UK economy*, part of which will relate to direct healthcare costs and the rest to indirect costs. This is a significant sum and represents $16.7 \%$ of the current Health and Social Care Budget of $£ 140$ billion.

Given the likely deeply negative impact of the current crisis on the economy in the medium term, it is imperative that the UK finds effective ways to manage health costs going forward. Vitamin $D$ testing of serum 25(OH)D added to GP's routine tests with incentives for achieving levels of at least $40 \mathrm{ng} / \mathrm{ml}$ in patients has the potential to significantly reduce future healthcare costs.

* based on savings being the same percentage, $16.7 \%$, of total health costs as calculated in the paper.

Eshani King

2 May 2020. Updated 4 June.2020 


\section{References:}

1. HSJ "Exclusive: Deaths of NHS staff from COVID -19 analysed" 22 April 2020, Tim Cook, Emira Kursumovic, Simon Lennane,

2. Rapid response letter, Preventing a COVID-19 Pandemic, R Brown BMJ 2020;368:m810 and BMJ 2020;369:m1548,

3. Wacker M, Holick MF. Vitamin D - effects on skeletal and extra-skeletal health and the need for supplementation. Nutrients. 2013;5(1):111-148. Published 2013 Jan 10. doi:10.3390/nu5010111

4. Holick MF, Binkley NC, Bischoff-Ferrari HA, et al. Evaluation, treatment, and prevention of vitamin D deficiency: An Endocrine Society clinical practice guideline [published correction appears in J Clin Endocrinol Metab. 2011 Dec;96(12):3908]. J Clin Endocrinol Metab. 2011;96(7):1911-1930. doi:10.1210/jc.2011-0385

5. Papadimitriou DT. The Big Vitamin D Mistake. J Prev Med Public Health. 2017;50(4):278-281. doi:10.3961/jpmph.16.111

6. Bergman $\mathrm{P}$, Norlin AC, Hansen S, et al. Vitamin D3 supplementation in patients with frequent respiratory tract infections: a randomised and double-blind intervention study. BMJ Open. 2012;2(6):e001663. Published 2012 Dec 13. doi:10.1136/bmjopen-2012-001663

7. Weydert JA. Vitamin D in Children's Health. Children (Basel). 2014;1(2):208-226. Published 2014 Sep 12. doi:10.3390/children1020208

8. European Food Safety Authority Panel, "Scientific Opinion on the Tolerable Upper Level Intake Level of Vitamin D" ; EFSA Journal, 27 July 2012

9. Dr M Holick. Dec 2013. University Lecture, Boston The D-delightful vitamin D for health: https://www.youtube.com/watch?v=EP81YMvs4yl

10. Ramagopalan SV, Heger A, Berlanga AJ, et al. A ChIP-seq defined genome-wide map of vitamin $D$ receptor binding: associations with disease and evolution. Genome Res. 2010;20(10):1352-1360. doi:10.1101/gr.107920.110

11. Two Main Graphs - Deficiency and COVID: Reproduced with permission from Grassroots Health Nutrient Research Institute which has implemented the world's largest vitamin D nutrient field trial, D*action, since 2008: . https://www.grassrootshealth.net/blog/first-datapublished-covid-19-severity-vitamin-d-levels/

12. Lips, Paul \& Cashman, Kevin \& Lamberg-Allardt, Christel \& Bischoff-Ferrari, Heike \& Obermayer-Pietsch, Barbara \& Bianchi, Maria \& Stepan, Jan \& Fuleihan, Ghada \& Bouillon, Roger. (2019). MANAGEMENT OF ENDOCRINE DISEASE: Current vitamin D status in European and Middle East countries and strategies to prevent vitamin D deficiency; a position statement of the European Calcified Tissue Society. European Journal of Endocrinology. 180. 10.1530/EJE-18-0736.

13. Michael F. Holick, Neil C. Binkley, Heike A. Bischoff-Ferrari, Catherine M. Gordon, David A. Hanley, Robert P. Heaney, M. Hassan Murad, Connie M. Weaver, Guidelines for Preventing and Treating Vitamin D Deficiency and Insufficiency Revisited, The Journal of Clinical Endocrinology \& Metabolism, Volume 97, Issue 4, 1 April 2012, Pages 1153-1158, https://doi.org/10.1210/jc.2011-2601

14. Karani, Vimal \& Cavadino, Alana \& Berry, Diane \& Jorde, Rolf \& Dieffenbach, Aida \& Lu, Chen \& Alves, Alexessander \& Heerspink, Hiddo \& Tikkanen, Emmi \& Eriksson, Joel \& Wong, Andrew \& Mangino, Massimo \& Jablonski, Kathleen \& Nolte, Ilja \& Houston, Denise \& Ahluwalia, Tarunveer \& Van der Most, Peter \& Pasko, Dorota \& Zgaga, Lina \& Hyppönen, Elina. (2014). Association of vitamin D status with arterial blood pressure and hypertension risk: A mendelian randomisation study. The Lancet Diabetes and Endocrinology. 10.1016/S2213-8587(14)70113-5. 
15. Pfeifer M, Begerow B, Minne HW, Nachtigall D, Hansen C. Effects of a short-term vitamin D(3) and calcium supplementation on blood pressure and parathyroid hormone levels in elderly women. J Clin Endocrinol Metab. 2001;86(4):1633-1637. doi:10.1210/jcem.86.4.7393

16. Rostand SG. Ultraviolet light may contribute to geographic and racial blood pressure differences. Hypertension. 1997;30(2 Pt 1):150-156. doi:10.1161/01.hyp.30.2.150

17. Holick MF. Sunlight and vitamin D for bone health and prevention of autoimmune diseases, cancers, and cardiovascular disease. Am J Clin Nutr. 2004;80(6 Suppl):1678S-88S. doi:10.1093/ajcn/80.6.1678S

18. Hyppönen $E$, Läärä $E$, Reunanen $A$, Järvelin $M R$, Virtanen SM. Intake of vitamin D and risk of type 1 diabetes: a birth-cohort study. Lancet. 2001;358(9292):1500-1503. doi:10.1016/S01406736(01)06580-1

19. Barbara Boucher, Vitamin D, obesity and risk of diabetes, Lancet Diabetes and Endocrin. 2014; Vol2 I 5:361-362

20. Park SK, Garland CF, Gorham ED, BuDoff L, Barrett-Connor E (2018) Plasma 25hydroxyvitamin $D$ concentration and risk of type 2 diabetes and pre-diabetes: 12 -year cohort study. PLOS ONE 13(4): e0193070. https://doi.org/10.1371/journal.pone.0193070

21. Berridge MJ. Vitamin D deficiency and diabetes. Biochem J. 2017;474(8):1321-1332. Published 2017 Mar 24. doi:10.1042/BCJ20170042

22. Sassi F, Tamone C, D'Amelio P. Vitamin D: Nutrient, Hormone, and Immunomodulator. Nutrients. 2018;10(11):1656. Published 2018 Nov 3. doi:10.3390/nu10111656

23. Garland CF, Garland FC, Gorham ED, et al. The role of vitamin D in cancer prevention. Am J Public Health. 2006;96(2):252-261. doi:10.2105/AJPH.2004.045260

24. Crew KD, Gammon MD, Steck SE, et al. Association between plasma 25-hydroxyvitamin D and breast cancer risk. Cancer Prev Res (Phila). 2009;2(6):598-604. doi:10.1158/1940-6207.CAPR08-0138

25. Feskanich, Diane \& Fuchs, Charles \& Kirkner, Gregory \& Hankinson, Susan \& Hollis, Bruce \& Giovannucci, Edward. (2004). Plasma vitamin D metabolites and risk of colorectal cancer in women. Cancer Epidemiol Biomarkers Prev 13(9), 1502-08. Cancer epidemiology, biomarkers \& prevention : a publication of the American Association for Cancer Research, cosponsored by the American Society of Preventive Oncology. 13. 1502-8.

26. Sascha Abbas, Jakob Linseisen, Tracy Slanger, Silke Kropp, Elke Jonny Mutschelknauss, Dieter Flesch-Janys, Jenny Chang-Claude, Serum 25-hydroxyvitamin D and risk of post-menopausal breast cancer-results of a large case-control study, Carcinogenesis, Volume 29, Issue 1, January 2008, Pages 93-99, https://doi.org/10.1093/carcin/bgm240

27. Joan M Lappe, Dianne Travers-Gustafson, K Michael Davies, Robert R Recker, Robert $P$ Heaney, Vitamin D and calcium supplementation reduces cancer risk: results of a randomized trial, The American Journal of Clinical Nutrition, Volume 85, Issue 6, June 2007, Pages 15861591, https://doi.org/10.1093/ajcn/85.6.1586

28. Bruce Hollis PhD University of California presentation; Results of a Prostate Cancer/Vitamin D Trial: Effectiveness Safety Recommendations, 15 Jan 2015 https://www.youtube.com/watch?v=QrU1yrmNlqc

29. Czarnecki, Dr \& Meehan, C \& Bruce, F. (2009). The vitamin D status of Australian dermatologists. Clinical and experimental dermatology. 34. 624-5. 10.1111/j.13652230.2008.03002.x.

30. Reinholz M, Ruzicka T, Schauber J. Vitamin D and its role in allergic disease. Clin Exp Allergy. 2012;42(6):817-826. doi:10.1111/j.1365-2222.2011.03923.x

31. Agrawal T, Gupta GK, Agrawal DK. Vitamin D supplementation reduces airway hyperresponsiveness and allergic airway inflammation in a murine model. Clin Exp Allergy. 2013;43(6):672-683. doi:10.1111/cea.12102 
32. Gwyer Findlay E, Currie SM, Davidson DJ. Cationic host defence peptides: potential as antiviral therapeutics. BioDrugs. 2013;27(5):479-493. doi:10.1007/s40259-013-0039-0

33. Quraishi SA, De Pascale G, Needleman JS, et al. Effect of Cholecalciferol Supplementation on Vitamin D Status and Cathelicidin Levels in Sepsis: A Randomized, Placebo-Controlled Trial. Crit Care Med. 2015;43(9):1928-1937. doi:10.1097/CCM.0000000000001148

34. Herr C, Shaykhiev R, Bals R. The role of cathelicidin and defensins in pulmonary inflammatory diseases. Expert Opin Biol Ther. 2007;7(9):1449-1461. doi:10.1517/14712598.7.9.1449

35. Agier J, Efenberger M, Brzezińska-Błaszczyk E. Cathelicidin impact on inflammatory cells. Cent Eur J Immunol. 2015;40(2):225-235. doi:10.5114/ceji.2015.51359

36. Barlow PG, Svoboda P, Mackellar A, Nash AA, York IA, Pohl J, et al. (2011) Antiviral Activity and Increased Host Defense against Influenza Infection Elicited by the Human Cathelicidin LL37. PLoS ONE 6(10): e25333. https://doi.org/10.1371/journal.pone.0025333

37. Greiller CL, Martineau AR. Modulation of the immune response to respiratory viruses by vitamin D. Nutrients. 2015;7(6):4240-4270. Published 2015 May 29. doi:10.3390/nu7064240

38. Liu PT, Stenger S, Li H, et al. Toll-like receptor triggering of a vitamin D-mediated human antimicrobial response. Science. 2006;311(5768):1770-1773. doi:10.1126/science.1123933

39. Dancer RC, Parekh $D$, Lax $S$, et al. Vitamin $D$ deficiency contributes directly to the acute respiratory distress syndrome (ARDS). Thorax. 2015;70(7):617-624. doi:10.1136/thoraxjnl2014-206680

40. Xu J, Yang J, Chen J, Luo Q, Zhang Q, Zhang H. Vitamin D alleviates lipopolysaccharide-induced acute lung injury via regulation of the renin-angiotensin system. Mol Med Rep. 2017;16(5):7432-7438. doi:10.3892/mmr.2017.7546

41. Yang, Jelena \& Zhang, Hanxiao \& Xu, Jianjian. (2016). Effect of Vitamin D on ACE2 and Vitamin $D$ receptor expression in rats with LPS-induced acute lung injury. 25. 1284-1289.

10.3760/cma.j.issn.1671-0282.2016.12.016.

42. Linda A Linday; Richard D Shindledecker; Juan Tapia-Mendoza; Jay N Dolitsky, 2004 Nov Effect of daily cod liver oil and a multivitamin-mineral supplement with selenium on upper respiratory tract pediatric visits by young, inner-city, Latino children: randomized pediatric sites. Ann. Otol. Rhinol. Laryngol Volume 113: 891-901 ISSN: 0003-4894

43. Urashima M, Segawa T, Okazaki M, Kurihara M, Wada Y, Ida H. Randomized trial of vitamin D supplementation to prevent seasonal influenza A in schoolchildren. Am J Clin Nutr. 2010;91(5):1255-1260. doi:10.3945/ajcn.2009.29094

44. Carlos A Carmargo et al, Randomised trial of vitamin D supplementation and risk of acute respiratory infection in Mongolia, Pediatrics, Sep 2012 ;Volume 130 No3,:e561-7. DOI: https://doi.org/10.1542/peds.2011-3029

45. Adrian R, Martineau et al, Vitamin D supplementation to prevent acute respiratory tract infections: systematic review and meta-analysis of individual participant data, $B M J$ 2017;356:i6583,

46. Jolliffe DA, Griffiths CJ, Martineau AR. Vitamin D in the prevention of acute respiratory infection: systematic review of clinical studies. J Steroid Biochem Mol Biol. 2013;136:321-329. doi:10.1016/j.jsbmb.2012.11.017

47. Beard JA, Bearden A, Striker R. Vitamin D and the anti-viral state. J Clin Virol. 2011;50(3):194200. doi:10.1016/j.jcv.2010.12.006

48. Greiller, C.L.; Martineau, A.R.,Modulation of the immune response to respiratory viruses by vitamin D. Nutrients 2015;7,:4240-4270

49. Wei R, Christakos S. Mechanisms Underlying the Regulation of Innate and Adaptive Immunity by Vitamin D. Nutrients. 2015;7(10):8251-8260. Published 2015 Sep 24.

doi:10.3390/nu7105392 
50. Zhou YF, Luo BA, Qin LL. The association between vitamin D deficiency and communityacquired pneumonia: A meta-analysis of observational studies. Medicine (Baltimore). 2019;98(38):e17252. doi:10.1097/MD.0000000000017252

51. Bergman $P$, Norlin AC, Hansen $S$, et al. Vitamin D3 supplementation in patients with frequent respiratory tract infections: a randomised and double-blind intervention study. BMJ Open. 2012;2(6):e001663. Published 2012 Dec 13. doi:10.1136/bmjopen-2012-001663

52. Sabetta JR, DePetrillo P, Cipriani RJ, Smardin J, Burns LA, Landry ML. Serum 25hydroxyvitamin $d$ and the incidence of acute viral respiratory tract infections in healthy adults. PLoS One. 2010;5(6):e11088. Published 2010 Jun 14.

doi:10.1371/journal.pone.0011088

53. Murdoch DR, Slow S, Chambers ST, et al. Effect of vitamin D3 supplementation on upper respiratory tract infections in healthy adults: the VIDARIS randomized controlled trial. JAMA. 2012;308(13):1333-1339. doi:10.1001/jama.2012.12505

54. Rees JR, Hendricks K, Barry EL, et al. Vitamin D3 supplementation and upper respiratory tract infections in a randomized, controlled trial. Clin Infect Dis. 2013;57(10):1384-1392. doi:10.1093/cid/cit549

55. Schöttker B, Haug U, Schomburg L, et al. Strong associations of 25-hydroxyvitamin D concentrations with all-cause, cardiovascular, cancer, and respiratory disease mortality in a large cohort study. Am J Clin Nutr. 2013;97(4):782-793. doi:10.3945/ajcn.112.047712 Heath AK, Kim IY, Hodge AM, English DR, Muller DC. Vitamin

56. Heath AK, Kim IY, Hodge AM, English DR, Muller DC. Vitamin D Status and Mortality: A Systematic Review of Observational Studies. Int J Environ Res Public Health. 2019;16(3):383. Published 2019 Jan 29. doi:10.3390/ijerph16030383 Garland CF, Kim JJ, Mohr SB, et al. Metaanalysis of all-cause mortality according to serum 25-hydroxyvitamin D. Am J Public Health. 2014;104(8):e43-e50. doi:10.2105/AJPH.2014.302034

57. Armin Zittermann, Simona lodice, Stefan Pilz, William B Grant, Vincenzo Bagnardi, Sara Gandini, Vitamin D deficiency and mortality risk in the general population: a meta-analysis of prospective cohort studies, The American Journal of Clinical Nutrition, Volume 95, Issue 1, January 2012, Pages 91-100, https://doi.org/10.3945/ajcn.111.014779

58. Johanna M. Geleijnse, Cees Vermeer, Diederick E. Grobbee, Leon J. Schurgers, Marjo H. J. Knapen, Irene M. van der Meer, Albert Hofman, Jacqueline C. M. Witteman, Dietary Intake of Menaquinone Is Associated with a Reduced Risk of Coronary Heart Disease: The Rotterdam Study, The Journal of Nutrition, Volume 134, Issue 11, November 2004, Pages 3100-3105, https://doi.org/10.1093/in/134.11.3100

59. Reddy P, Edwards LR. Magnesium Supplementation in Vitamin D Deficiency. Am J Ther. 2019;26(1):e124-e132. doi:10.1097/MJT.0000000000000538

60. Uwitonze, Anne-Marie \& Razzaque, Mohammed. (2018). Role of Magnesium in Vitamin D Activation and Function. The Journal of the American Osteopathic Association. 118. 10.7556/jaoa.2018.037

61. Holick MP University lecture Boston Dec2012, Sunlight and Your Health: An EnLIGHTening Perspective. 7 Jan 2015 and Vitamin D Measurement the Key to Change 16 Jan 2015

62. Holick MF. Vitamin D: a d-lightful solution for health. J Investig Med. 2011;59(6):872-880. doi:10.2310/JIM.0b013e318214ea2d

63. Lehmann, Ulrike \& Hirche, Frank \& Stangl, Gabriele \& Hinz, Katja \& Westphal, Sabine \& Dierkes, Jutta. (2013). Bioavailability of Vitamin D-2 and D-3 in Healthy Volunteers, a Randomized Placebo-Controlled Trial. The Journal of clinical endocrinology and metabolism. 98. 10.1210/jc.2012-4287.

64. Laura Tripkovic, Helen Lambert, Kathryn Hart, Colin P Smith, Giselda Bucca, Simon Penson, Gemma Chope, Elina Hyppönen, Jacqueline Berry, Reinhold Vieth, Susan Lanham-New, Comparison of vitamin $D_{2}$ and vitamin $D_{3}$ supplementation in raising serum 25- 
hydroxyvitamin D status: a systematic review and meta-analysis, The American Journal of Clinical Nutrition, Volume 95, Issue 6, June 2012, Pages 1357-1364, https://doi.org/10.3945/ajcn.111.031070

65. John N Hathcock, Andrew Shao, Reinhold Vieth, Robert Heaney, Risk assessment for vitamin D, The American Journal of Clinical Nutrition, Volume 85, Issue 1, January 2007, Pages 6-18, https://doi.org/10.1093/ajcn/85.1.6

66. Taylor PN, Davies JS. A review of the growing risk of vitamin D toxicity from inappropriate practice. Br J Clin Pharmacol. 2018;84(6):1121-1127. doi:10.1111/bcp.13573

67. William B. Grant et al "Evidence that Vitamin D Supplementation Could Reduce Risk of Influenza and COVID-19 Infections and Deaths" April 2020:https://www.grassrootshealth.net/wp-content/uploads/2020/04/Grant-GRH-Covidpaper-2020.pdf

68. Jaillon, S., Berthenet, K. \& Garlanda, C. Sexual Dimorphism in Innate Immunity. Clinic Rev Allerg Immunol 56, 308-321 (2019). https://doi.org/10.1007/s12016-017-8648-x

69. Lotter, H., Altfeld, M. Sex differences in immunity. Semin Immunopathol 41, 133-135 (2019). https://doi.org/10.1007/s00281-018-00728-x

70. Sanghera DK, Sapkota BR, Aston CE, Blackett PR. Vitamin D Status, Gender Differences, and Cardiometabolic Health Disparities. Ann Nutr Metab. 2017;70(2):79-87. doi:10.1159/000458765

71. Raharusun, Prabowo and Priambada, Sadiah and Budiarti, Cahni and Agung, Erdie and Budi, Cipta, Patterns of COVID-19 Mortality and Vitamin D: An Indonesian Study (April 26, 2020 updated 6 May). Available at SSRN: https://ssrn.com/abstract=3585561 or http://dx.doi.org/10.2139/ssrn.3585561

72. Anindita Banerjee, Vineet Kumar Khemka (2017) Augmentation of anticoagulant effect with vitamin D: possible therapeutic target for venous thromboembolism. Int J Hematol Blo Dis 2(1):1-5. Int J Hematol Blo Dis 2(1):1-5.

73. The Vitamin D Solution, book by Michael F Holick

74. Grant, W. B., Cross, H. S., Garland, C. F., Gorham, E. D., Moan, J., Peterlik, M., Porojnicu, A. C., Reichrath, J., \& Zittermann, A. (2009). Estimated benefit of increased vitamin D status in reducing the economic burden of disease in western Europe. Progress in Biophysics and Molecular Biology, 99(2-3), 104-113. https://doi.org/10.1016/j.pbiomolbio.2009.02.003

75. Gauree Gupta Konijeti, Pankaj Arora, Matthew R. Boylan, Yanna Song, Shi Huang, Frank Harrell, Christopher Newton-Cheh, Dillon O'Neill, Joshua Korzenik, Thomas J. Wang, Andrew T. Chan, Vitamin D Supplementation Modulates T Cell-Mediated Immunity in Humans: Results from a Randomized Control Trial, The Journal of Clinical Endocrinology \& Metabolism, Volume 101, Issue 2, 1 February 2016, Pages 533-538, https://doi.org/10.1210/jc.2015-3599

76. Carsetti, Rita \& Quintarelli, Concetta \& Quinti, Isabella \& Piano Mortari, Eva \& Zumla, Alimuddin \& Ippolito, Giuseppe \& Locatelli, Franco. (2020). The immune system of children: the key to understanding SARS-CoV-2 susceptibility? The Lancet Child \& Adolescent Health. 10.1016/S2352-4642(20)30135-8.

77. Cornelis Kennedy, Rein Willemze, Frank R.de GruijJan, N.Bouwes Bavinck, Chris D. Bajdik, The Influence of Painful Sunburns and Lifetime Sun Exposure on the Risk of Actinic Keratoses, Seborrheic Warts, Melanocytic Nevi, Atypical Nevi, and Skin Cancer, Journal of Investigative Dermatology:Volume 120, Issue 6, June 2003:1087-1093Ekwaru JP, Zwicker JD, Holick MF,

78. Giovannucci E, Veugelers PJ. The importance of body weight for the dose response relationship of oral vitamin $D$ supplementation and serum 25 -hydroxyvitamin $D$ in healthy volunteers. PLoS One. 2014;9(11):e111265. Published 2014 Nov 5. doi:10.1371/journal.pone.0111265

79. Hossein-nezhad A, Spira A, Holick MF. Influence of vitamin D status and vitamin D3 supplementation on genome wide expression of white blood cells: a randomized doubleblind clinical trial. PLoS One. 2013;8(3):e58725. doi:10.1371/journal.pone.0058725 
80. Veugelers PJ, Ekwaru JP. A statistical error in the estimation of the recommended dietary allowance for vitamin D. Nutrients. 2014;6(10):4472-4475. Published 2014 Oct 20. doi:10.3390/nu6104472

81. Preliminary report: https://www.thenewamerican.com/usnews/health-care/item/35581sunshine-increases-vitamin-d-and-may-build-resistance-to-coronavirus

82. Spiro A, Buttriss JL. Vitamin D: An overview of vitamin D status and intake in Europe. Nutr Bull. 2014;39(4):322-350. doi:10.1111/nbu.12108

83. Jain SK, Micinski D. Vitamin D upregulates glutamate cysteine ligase and glutathione reductase, and GSH formation, and decreases ROS and MCP-1 and IL-8 secretion in highglucose exposed U937 monocytes. Biochem Biophys Res Commun. 2013;437(1):7-11. doi:10.1016/j.bbrc.2013.06.004

84. Theron, Michel \& Huang, Kao-Jean \& Chen, Yu-Wen \& Liu, Ching-Chuan \& Lei, Huan-Yao. (2005). A probable role for IFN- $\gamma$ in the development of a lung immunopathology in SARS. Cytokine. 32. 30-8. 10.1016/j.cyto.2005.07.007.

85. Zhang Y, Li J, Zhan Y, et al. Analysis of serum cytokines in patients with severe acute respiratory syndrome. Infect Immun. 2004;72(8):4410-4415. doi:10.1128/IAI.72.8.44104415.2004

86. Wu D, Yang XO. TH17 responses in cytokine storm of COVID-19: An emerging target of JAK2 inhibitor Fedratinib [published online ahead of print, 2020 Mar 11]. J Microbiol Immunol Infect. 2020;S1684-1182(20)30065-7. doi:10.1016/j.jmii.2020.03.005

87. Chang SH, Chung Y, Dong C. Vitamin D suppresses Th17 cytokine production by inducing C/EBP homologous protein (CHOP) expression. J Biol Chem. 2010;285(50):38751-38755. doi:10.1074/jbc.C110.185777

88. Rhodes LE, Webb AR, Fraser HI, et al. Recommended summer sunlight exposure levels can produce sufficient ( $>$ or $=20 \mathrm{ng} \mathrm{ml}(-1)$ ) but not the proposed optimal ( $>$ or $=32 \mathrm{ng} \mathrm{ml}(-1)$ ) 25(OH)D levels at UK latitudes. J Invest Dermatol. 2010;130(5):1411-1418. doi:10.1038/jid.2009.417

89. Lindqvist PG, Epstein E, Nielsen K, Landin-Olsson M, Ingvar C, Olsson H. Avoidance of sun exposure as a risk factor for major causes of death: a competing risk analysis of the Melanoma in Southern Sweden cohort. J Intern Med. 2016;280(4):375-387. doi:10.1111/joim.12496 